DOI 10.17150/978-5-7253-3001-4.19

В.Б. ЛАПЕРДИН

УДК 94(571)《1930/37»

ББК 63/3(253)614-2

\title{
ХЛЕБОЗАГОТОВИТЕЛЬНЫЕ КАМПАНИИ 1930-Х ГОДОВ В ЗАПАДНО-СИБИРСКОМ КРАЕ: ОТНОШЕНИЯ ЦЕНТРА И РЕГИОНАЛЬНОГО РУКОВОДСТВА*
}

В статье рассматриваются взаимоотношения Западно-Сибирского крайкома и центрального руководства страны по вопросу хлебозаготовительных кампаний в 1930-е гг. Особое внимание отведено роли представителей регионального уровня власти в проводившейся сталинским правительством аграрной политике. Хлебозаготовительные планы стали результатом длительных переговоров между Центром и регионалами, что было одной из причин изменения заготовительной системы в 1933 г. Являясь проводниками сталинской политики в Западной Сибири, местные власти старались ее корректировать, сделав осуществимой на практике.

Ключевые слова: аграрная политика государства, хлебозаготовки, крестьянство, Сибирь, Р.И. Эйхе.

V.B. LAPERDIN

\section{GRAIN PROCUREMENT CAMPAIGNS OF 1930s IN WEST SIBERIAN REGION: RELATIONSHIPS BETWEEN CENTRAL AND REGIONAL AUTHORITIES}

Article contains analysis of relationships between West Siberian Regional Committee and central authorities on the issue of grain procurement campaigns in 1930s. Special attention is paid to the role of regional representatives in agrarian policy, conducted by Stalinist government. Grain procurement plans were made as a result of long-time negotiations between

* Публикация подготовлена при финансовой поддержке РФФИ, проект № 19-09-00031 «Аграрный строй в Сибири в 1930-е гг.: становление и функционирование колхозной системы». 
Central and regional authorities. It was one of the reasons for the change in procurement system in 1933. Local authorities, providing Stalinist policy in West Siberia, tried to correct it, make it feasible in practice.

Keywords: agrarian policy, grain procurement, peasantry, Siberia, R.I. Aihe.

Хлебозаготовительные кампании в 1930-е гг. стали основным средством получения зерна государством. Цель данной статьи - охарактеризовать отношения в ходе хлебозаготовок Центра и руководства Западно-Сибирского края, образованного в 1930 г. и упраздненного в 1937 г. Говоря о руководстве Западно-Сибирского края, основное внимание будет уделено действиям первого секретаря крайкома Р.И. Эйхе. Под Центром подразумевается совокупность организаций союзного значения, задействованных в хлебозаготовительной кампании, в первую очередь Политбюро ЦК ВКП(б), устанавливавшего размеры заданий (планов) и сроки их выполнения. Решение данного вопроса поможет лучше понять роль представителей регионального уровня власти в проводившейся сталинским правительством аграрной политике.

Первоначальный план для Сибирского края, установленный в хлебозаготовительную кампанию 1930/31 г., составлял 115 млн пуд. Региональное руководство посчитало его завышенным и приняло решение создать специальную комиссию, возглавляемую заместителем председателя крайисполкома Н.С. Базаровым. Ее целью было составление нового, сниженного плана, отстаивать который отправился в Москву заведующий крайторготделом А.Н. Злобин. Ему удалось убедить Центр в необходимости снижения задания. Однако вместо предлагавшихся регионалами 92 млн пуд., было принято решение остановиться на 107 млн пуд. Из них 85 должно быть заготовлено в новообразованном Западно-Сибирском крае. Однако в последствии Центр изменил свои планы - в связи с хорошим урожаем в ряде регионов на места были разосланы директивы об увеличении поставок зерна. 15 сентября 1930 г. Политбюро ЦК ВКП(б) постановило дать Западной Сибири дополнительное задание в 7 млн пуд. 28 ноября последовало еще одно распоряжение Политбюро - в порядке встречных планов заготовить еще столько же. Первый секретарь Западно-Сибирского крайкома Р.И. Эйхе пытался доказать И.В. Сталину невыполнимость нового плана: «положение с хлебозаготовками очень напряженное, и реальным можно считать лишь то, чтобы путем встречных планов в единоличном секторе только покрыть неизбежный недобор по плану колхозного сектора, т.е. выполнить общий план по краю» [1, оп. 2, д. 150, л. 111]. Его доводы остались без внимания и 28 ноября 1931 г. встречное задание, считавшееся необязательным, было включено в основной план. Всего в кампанию 1930/31 г. в Западно-Сибирском крае было заготовлено 81,3 млн пуд., или 82,9 \% годового задания. Не удалось выполнить не только встречные планы, но и основной. 
Кампания 1930/31 г. проходила в совершенно иных социально-политических условиях. Уровень коллективизации в Западно-Сибирском крае увеличился с 20,9 \% в июле 1930 г. до 52,5 \% в июле 1931 г. В последующем он продолжал расти к июлю 1932 г. составив 61,2%. Аграрная экономика Сибири перестала быть крестьянской, а крестьянское хозяйство - ее основной организационно-производственной ячейкой [5, с. 73]. Доминирующая роль перешла к социалистическому сектору. Уверенность в преимуществе коллективных хозяйств стала одной из причин увеличения заготовительных планов. Первоначальное задание, данное 25 июля 1931 г. Западной Сибири составляло 100 млн пуд.

Ситуацию усугубляла засуха, поразившая ряд районов края. Если в урожайный 1930 г. валовой сбор зерновых составил 5 516,2 тыс. т, то в 1931 г., несмотря на 19\%-й рост посевных площадей, по данным ЦУНХУ, удалось собрать 3 199,3 тыс. т [6, с. 270]. По сведениям крайземуправления, от непогоды в той или иной степени пострадало 55 районов. Недобор зерновой продукции составлял 1200 тыс. т. [1, оп. 2, д. 352, л. 132].

В условиях возросшей личной власти И.В. Сталина, старавшегося держать региональных руководителей под строгим контролем, создавать специальную комиссию по определению урожая, становилось опасно. Могли последовать обвинения в антигосударственной деятельности и оппортунизме. Однако у регионалов оставались пути влияния на решения Центра: они отстаивали собственные интересы при встрече с представителями Политбюро или же в переписке с ними.

В своем письме, адресованном в Центр, Р.И. Эйхе утверждал, что выполнение заготовительного задания в условиях засухи невозможно и только «дезорганизует хлебозаготовки, вызовет политические осложнения в деревне и резко сократит посевные площади в будущем году» [1, оп. 1, д. 412 б, л. 29]. Глава края просил уменьшить задание до 65 млн пуд., считая это более реальным для условий Западной Сибири. Посетив Москву в августе 1931 г., Р.И. Эйхе вновь настаивал на снижении плана [4, с. 99]. Прошения о пересмотре хлебозаготовительных заданий поступали и из других областей страны. Политбюро ЦК ВКП(б) под напором краевых организаций было вынуждено умерить аппетиты. Однако просьба Р.И. Эйхе не была полностью удовлетворена, в частности, по причине позиции И.В. Сталина, не желавшего идти на столь значительные уступки [4, с. 100]. 25 августа 1931 г. Политбюро постановило заготовить в Западной Сибири 85 млн пуд. [2, с. 481]

Вопреки ожиданиям Центра, снижение годового плана не способствовало выполнению месячных заданий. Р.И. Эйхе не оставлял попыток умерить аппетиты руководства страны, ссылаясь на засуху и неурожай. На проходившем в конце октября 1931 г. пленуме ЦК ВКП(б) остро стоял вопрос о текущей заготовительной кампании. Краевые руководители просили Политбюро и лично И.В. Сталина снизить задания. Полит- 
бюро пришлось уменьшить планы по ряду краев и областей за счет их увеличения в более благополучных регионах страны. Поблажку получил и Западно-Сибирский край. Новое задание составляло 65 млн пуд. [2, с. 535]. Таким образом, Р.И. Эйхе удалось отстоять перед Центром предлагавшиеся еще летом контрольные цифры.

Характеризуя поведение руководства Западно-Сибирского края во время хлебозаготовок 1931/32 г., можно заключить, что, как и в предыдущую кампанию, оно отстаивало региональные интересы (в отличие, например, от генерального секретаря ЦК КП(б)У С.В. Косиора, утверждавшего, что Украина хлеб имеет, его надо только «уметь взять» [2, с. 528-530]. Позиция сибирских партийных и хозяйственных организаций объясняется нереальным первоначальным планом (100 млн пуд.), выдвинутым Политбюро ЦК ВКП(б), и неурожаем 1931 г., сократившим возможности деревни.

План хлебозаготовительной кампании 1932/33 г. составлял 85 млн пуд. Как и в предыдущие годы регионалы пытались отстаивать собственные интересы. Однако в условиях усилившегося давления со стороны Политбюро о снижении плана речи уже не шло. Тем не менее, действия региональных властей соответствовали ранее сложившейся схеме: они пытались корректировать аграрную политику руководства страны с целью сделать ее реализуемой на практике, при этом отводя от себя возможный удар, возникавший в случае, если требования Москвы окажутся невыполненными. Так, руководство Западной Сибири попыталось отсрочить окончание хлебозаготовок в совхозах до 1 марта 1933 г., обосновывая это трудностями обмолота и вывозки хлеба в зимних условиях $[4$, с. 240]. Центр пошел на некоторые уступки и разрешил окончить сдачу хлеба в совхозах к 1 фревраля 1933 г. [4, с. 255]. Окончание хлебозаготовительной кампании, несмотря на невыполнение совхозами своих обязательств, было объявлено 21 января 1933 г. Западно-Сибирским крайком в специальном постановлении.

В 1933 г. произошло изменение законодательства в области хлебозаготовок. Существовавшая до этого контрактационная система отличалась сверхнормативным уровнем отчуждения и нестабильностью заготовительных планов, зачастую менявшихся в течение года в сторону увеличения. При этом дополнительные задания получали в первую очередь колхозы, достигшие производственных успехов и выполнившие заготовительные планы. Данный порядок подрывал их экономику и лишал стимулов для расширения сельхозпроизводства, переживавшего глубокий кризис как в стране в целом, так и в Сибири. Региональные власти неоднократно сигнализировали Центру о создавшемся тяжелом положении, прося Политбюро ЦК ВКП(б) снизить завышенные хлебозаготовительные планы. Первым лицам страны приходилось считаться с мнением регионалов, подкреплявшимся неутешительными сведения- 
ми о ходе кампаний. Существовавшая хлебозаготовительная система не отвечала не только интересам местных властей, которые вели постоянную дискуссию с Москвой по поводу размеров хлебозаготовительных планов, но и задачам Центра. От неустойчивого поступления хлеба зависел ход индустриализации. Государству требовалось обеспечить продовольствием население бурно растущих городов и вывозить хлеб за границу для получения валюты. Гарантировать точное поступление хлеба в заранее запланированных объемах контрактационная система уже не могла. Поэтому в 1933 г. государство реформировало систему хлебозаготовок. Контрактация основных видов сельхозпродукции была заменена обязательными поставками, которые официально имели статус налога, оставались неизменными в течение хлебозаготовительной кампании и исчислялись по посевным площадям.

Одним из нововведений в хлебозаготовительную кампанию 1933 г. в Западно-Сибирском крае, как и в других регионах страны, стало широкое распространение системы дополнительных фондов. Еще в августе первый секретарь крайкома Р.И. Эйхе писал И.В. Сталину о неурожае в прилегающих к Казахстану районах, где ожидаемый сбор составил от 2 до 4 ц/га. Несмотря на это, в целом по региону в 1933 г. урожайность составляла около 9 ц/га. Но для помощи засушливым районам, а также тем колхозам, где ожидаемая урожайность не подтвердилась в ходе сбора и обмолота хлеба, требовалось предоставить льготы. Их предполагалось выделять, используя разницу между утвержденным правительством планом зернопоставок и фактически распределенным по краю. Эта дополнительная страховка составляла порядка 2,8 млн пуд. Ее Р.И. Эйхе и хотел использовать для предоставления льгот. Политбюро ЦК ВКП(б) одобрило его план 28 августа, однако сократило фонд до 1 млн пуд. [3, с. 98]. Тем не менее это была маленькая победа в отстаивании региональных интересов. Тогда же крайком создал специальную комиссию во главе с одним из его членов - А.Н. Злобиным [1, оп. 1, д. 451 , л. 108]. Основной ее задачей являлось рассмотрение прошений районных властей о предоставлении скидки неурожайным колхозам. После заключения комиссии решение утверждалось крайкомом и колхозы получали скидку, либо же просьба отклонялась. Со временем фонд дополнительной страховки увеличивался, превысив к концу года 3 млн пуд.

Хлебозаготовительная кампания 1934 г. проходила в условиях засухи и неурожая в юго-западной части СССР. Поэтому восточные регионы получили дополнительные задания. В том числе Западно-Сибирский край, где должны были засеять сверх плана 450 тыс. га. Всего же было засеяно 8095,3 тыс. га. Краевое задание по всем секторам с учетом гарнцевого сбора составляло 123,5 млн пуд. Ход заготовок, не устраивающий Центр, и провал августовского задания, вынудил регионалов просить снизить месячные планы. Краевые власти ссылались на недород в восточных 
и центральных районах края, а также частые дожди в конце лета, тормозившие ход хлебоуборочных работ. В ответ была получена весьма жесткая по своему тону телеграмма, в которой вина за провал хлебозаготовок возлагалась на местные власти [1, оп. 2, д. 544, л. 99-101]. Более того, в начале сентября в Сибирь прибыл В.М. Молотов. Основной целью его приезда было активизировать работу краевого руководства для скорейшего выполнения заготовительного плана. Усиленный нажим со стороны Москвы дал свои результаты, тем не менее, завышенный сентябрьский план выполнен не был. В середине октября в Западную Сибирь прибыл секретарь ЦК ВКП(б) Л.М. Каганович, принявший участие 15 октября в заседании бюро крайкома, где специально оговаривались сроки окончания хлебозаготовительной кампании в регионе - к 1 ноября [1, оп. 2, д. 640, л. 33-34 об.]. В результате нажима со стороны Центра, краевым властям удалось в течение октября собрать рекордный объем хлеба, выполнив к концу месяца обязательство перед государством на 101 \%. Таким образом, в 1934 г. руководство Западно-Сибирского края, оказавшись под жестким давлением со стороны Москвы, не смогло отстоять региональные интересы. Столкнувшись с позицией регионалов, Центру пришлось отправить за Урал двух высокопоставленных эмиссаров, чтобы они на месте возглавили ход хлебозаготовительной кампании.

В 1935 г. сложилась противоположная ситуация - в основных хлебопроизводящих регионах страны удалось собрать хороший урожай, в то время как Западно-Сибирский край поразила засуха, по своим масштабам сравнимая с бедствием 1931 г. Урожайность зерновых по данным ЦУНХУ составляла 6,4 ц/га [7, с. 337, 338], а валовый сбор хлебов уступал показателям предыдущего года на 34 \%. С целью избежать нового голода, Р.И. Эйхе просил у Центра оказать беспрецедентную помощь - помочь колхозам края семенной и продовольственной ссудой объемом 15 млн пуд., отсрочить взимание ранее выданных ссуд и предоставить дополнительный фонд скидок по зернопоставкам в размере 2 млн пуд. Москва удовлетворила почти все требования регионалов. К 1935 г. государству удалось накопить достаточный хлебный резерв, а обострять продовольственную ситуацию в одном из зерновых регионов было чревато негативными последствиями. В крае удалось заготовить 85 млн пуд., таким образом выполнив план, а региональному руководству удалось избежать нового массового голода.

Хлебозаготовительная кампания 1936 г. проходила в благоприятных для Западной Сибири погодных условиях. Хотя ряд юго-западных районов вновь поразила засуха и недород, ставшие здесь уже регулярными. Р.И. Эйхе докладывал в Москву: «При хорошем урожае в большинстве районов края в текущем году, все районы Кулундинской степи и значительная часть смежных с ними, подвергшиеся сильной засухи, собрали весьма низкий урожай. 20 районов имеют урожай зерновых в среднем 
2,6 цент[еров] с га, а в отдельных районах, так например, в Славгородском намолочено лишь 1,1 цент[ера] с га и в Ново-Киевском - 0,9 цент[ера] с га» $[1$, оп. 2 , д. 796, л. 7]. Первый секретарь крайкома просил разрешения снизить заготовительные планы. Центр, накопивший к тому времени достаточный запас хлебного государственного фонда, вновь решил пойти навстречу регионалам. В конце октября 1936 г. было уменьшено задание по обязательным поставкам колхозов на 1,5 млн пуд., а также снижен на 3,3 млн пуд. план сбора натуроплаты МТС. Вслед за этим в ноябре скорректирован план сдачи хлеба совхозов - им «простили» 1 млн пуд. Кроме того, в эту заготовительную кампанию с целью стимулирования колхозного производства произошло снижение норм зернопоставок.

На ход хлебозаготовительной кампании в Западно-Сибирском крае значительно повлияли административно-территориальные изменения - разделение края на Новосибирскую область и Алтайский край. А также проведение репрессий в рамках политики Большого террора. Многие управленцы, отвечавшие за организацию и проведение заготовок, были репрессированы, что негативно отразилось на поступлении зерна государству. Кроме того, новые региональные власти больше внимания уделяли не хозяйственно-политическим кампаниям, а проведению репрессий. Тем не менее, заготовительный план в целом по Западной Сибири был перевыполнен, что связано во многом с высоким урожаем - в этот год удалось собрать 11,6 ц/га зерновых. Какой-либо заметной полемики между Центром и регионалами по вопросу хлебозаготовок не происходило вследствие смены краевого руководства, проведения репрессий и высоких показателей сбора зерновых.

Таким образом, в 1930-х гг. хлебозаготовительная система отличалась динамичностью, изменяясь в соответствии с аграрной политикой государства. Власти искали оптимальный способ изъятия зерна из деревни. Основной проблемой для регионального руководства стала неопределенность планов, изменявшихся в течение года в зависимости от потребностей Центра. Размеры окончательного регионального задания стали предметом жаркого спора между Москвой и представителями Западно-Сибирского крайкома, пытавшимися отстоять собственные интересы. Подобного стиля поведения придерживались и многие другие региональные руководители. Политбюро пришлось преодолевать сопротивление регионалов каждый раз при установлении и изменении заготовительных планов, что не устраивало ни одну из сторон. Это стало основной причиной изменения заготовительной политики в 1933 г. Контрактация основных видов сельхозпродукции была заменена обязательными поставками, которые официально имели статус налога. Встречные планы строго запрещались. Центр пошел на уступку региональным властям. Однако за ним оставалось конечное слово при установлении планов посевных площадей, исходя из которых, в свою очередь, определялись хлебозаготовительные планы. Кроме того, 
начала действовать система скидок, позволившая уменьшать задания неурожайным районам и избежать возникновения локального голода. Их размеры для регионов устанавливались Москвой, в то время как местное руководство отвечало за оперативное управление фондом скидок. Таким образом, центральные власти нашли наиболее приемлемый на тот момент способ изъятия зерна из деревни, что стало возможным благодаря диалогу между Москвой и краевым руководством.

\section{Список использованной литературы и источников}

1. Государственный архив Новосибирской области. - Ф. П-3.

2. Голод в СССР. 1929-1934 : [сб. документов] : в 3 т. / отв. сост. В. В. Кондрашин. - Т. 1 : Лето 1933-1934 : в 2 кн.- М. : РОССПЭН, 2011. - Кн. 1. - 656 с.

3. Голод в СССР. 1929-1934 : [сб. документов] : в 3 т. / отв. сост. В. В. Кондрашин. - Т. 3 : Лето 1933-1934. - М. : РОССПЭН, 2011. — 960 с.

4. Дэвис Р. Годы голода: Сельское хозяйство СССР, 1931-1933 / Р. Дэвис, С. Уиткрофт. - М. : РОССПЭН, 2011. - 539 с.

5. Сельское хозяйство Сибири в XX веке: проблемы развития и кризисы / В. А. Ильиных, С. Н. Андреенков, В. М. Рынков [и др.]. - Новосибирск : ИИ СО $\mathrm{PAH}, 2012 .-408 \mathrm{c}$. $1468 \mathrm{c}$

6. Сельское хозяйство СССР. Ежегодник. 1935. - М. : Сельхозгиз, 1936. -

7. Социалистическое строительство СССР: Стат. ежегодник. - М. : ЦУНХУ Госплана СССР — В/О «Союзоргучет», 1936. - 719 с.

\section{Информация об авторе}

Лапердин Вячеслав Борисович - кандидат исторических наук, младший научный сотрудник сектора аграрной истории Института истории СО РАН, 630090, г. Новосибирск, ул. Николаева, 8; e-mail: laperdin2011@mail.ru

\section{Author}

Vacheslav B. Laperdin - PhD in History, Sector of the Agricultural History, Institute of History Siberian Branch of the Russian Academy of Science, 8 Nikolaev St., 630090, Novosibirsk, Russia; e-mail: laperdin2011@mail.ru 